\title{
CULTURAS, IDENTIDADES E TERRITÓRIOS: A REINVENÇÃO DOS CONCEITOS MEDIADOS PELA LINGUAGEM
}

Ana Beatriz Santos dos Anjos ${ }^{1}$ Yvonélio Nery Ferreira ${ }^{2}$

RESUMO: Nos propomos a fazer neste trabalho uma breve discussão teórica dos conceitos de cultura, identidade e território, compreendendo o seu caráter "móvel", bem como a relação com os aspectos históricos, políticos e econômicos no qual estão inseridos. Hall (2006) afirma que é pela linguagem que significamos o mundo e damos sentido as nossas relações sociais. À medida que re-significamos o mundo e essas relações, mudamos também a forma como os expressamos por meio da linguagem. Haesbaert (2008) aborda a necessidade de pensarmos tais conceitos a partir de uma perspectiva integradora, pois abordá-los de forma dicotômica parece não corresponder mais à sociedade cada vez mais dinâmica na qual vivenciamos. A partir dessas discussões, abordamos as identidades territoriais a partir da pesquisa de Morais (2016), a fim de compreender esse conceito híbrido, bem como suas implicações históricas, políticas e econômicas no contexto da construção identitária dos acreanos.

PALAVRAS-CHAVE: Culturas. Identidades. Territórios.

\section{INTRODUÇÃO}

A linguagem é o meio pelo qual expressamos o mundo. É o "lugar" onde damos concretude às abstrações do cotidiano. Assim, os conceitos são criados e recriados porque o mundo está em constante movimento e, ainda assim, precisamos expressá-lo. Nesse sentido, é interessante discutir que os conceitos, bem como os seus significados vão sendo revisitados, repensados e reformulados no decorrer do tempo. Admitindo, pois, o caráter móvel e híbrido dos conceitos de cultura, identidade e território, nos propomos a fazer uma discussão teórica entorno desses conceitos, a fim de compreender os seus múltiplos significados e aplicações no mundo, mediados pela linguagem.

Sendo assim, iniciaremos as discussões a partir de Stuart Hall (2016) para apontar as diferentes definições do conceito de cultura, desde a mais tradicional, que relaciona a cultura somente a bens e produções artísticos culturais; passando por definições mais antropológicas, que compreendem a cultura a partir dos hábitos de um grupo; até a definição sociológica, a partir da qual a cultura é compreendida pelo conjunto de valores e práticas sociais compartilhadas por determinado grupo.

Por conseguinte, abordaremos o conceito de identidade com fundamento nas reflexões de Hall (2006), a fim de compreendê-lo no seu processo de ressignificação ocorrido por conta das mudanças sociais. Em seguida, desenvolveremos os conceitos que correspondem às unici-

1 Instituição: Universidade Federal do Acre, Orcid: https://orcid.org/0000-0002-6093-9461, E-mail: anabeatrizdosanjos@gmail.com 2 Instituição: Universidade Federal do Acre, Orcid: https://orcid.org/0000-0002-5907-4894, E-mail: yvoneryferreira@gmail.com 
dades, ou seja, conceitos rígidos e essencializados, tal como é problematizado por Haesbaert (2008). Além disso, discutiremos o conceito de identidade a partir das questões propostas por Chirif (2012).

A seguir, discorreremos sobre os conceitos de cultura, identidade e território numa perspectiva integradora proposta Haesbaert (2007). Nesse percurso, será possível compreender as relações imbricadas entre esses conceitos e discutiremos brevemente as identidades territoriais a partir da obra de Morais (2016). Embora reconheçamos que os conceitos de cultura, identidade e território de fato não abrangem toda a complexidade e pluralidade das relações sociais estabelecidas em diferentes "espaços", interessa-nos não somente compreender os seus significados - mas, sobretudo, suas aplicações no mundo - que expressamos ou que chegam até nós por meio da linguagem.

\section{OS CONCEITOS, SUAS REPRESENTAC̣ÕES E APLICAC̣ÕES NO MUNDO}

Imersos na literatura dos Estudos Culturais, há sempre que nos situarmos nas definições de cultura, identidade e território. É comum termos dificuldade em definir esses conceitos tão móveis e fluídos que se dissolvem facilmente ou que nunca parecem - por meio da linguagem - serem capazes de abranger o significado em sua completude, tendo em vista a sua natureza plural e heterogênea. Embora reconheçamos isso, é fato que a linguagem é o meio pelo qual atribuímos sentido ao mundo e o representamos por intermédio dos signos linguísticos, de modo que o conceito de cultura está intrinsecamente relacionado ao conceito de representação:

Mas o que a representação tem a ver com a 'cultura'? Que conexão existe entre 're-
presentação' e 'cultura'? Colocando em termos simples, cultura diz respeito a 'signi-
ficados compartilhados'. Ora, a linguagem nada mais é do que o meio privilegiado
pelo qual 'damos sentido' às coisas, onde o significado é produzido e intercambiado.
Significados só podem ser compartilhados pelo acesso comum à linguagem. Assim,
esta se torna fundamental para os sentidos e para a cultura e vem sendo invariavel-
mente considerada o repositório-chave de valores e significados culturais. (HALL,
2016, p. 17).

A partir desse breve conceito de cultura, abordado por Hall (2016), percebemos o caráter relacional desse conceito, pois a cultura é compreendida na relação que o sujeito estabelece com o outro, sobretudo, nas trocas, nos significados e nas interpretações compartilhadas sobre o mundo, mediada pela e por meio da linguagem. Nessa direção, interessa-nos compreender essa relação imbricada da linguagem na construção dos significados:

Mas como a linguagem constrói significados? Como sustenta o diálogo entre participantes de modo a permitir que eles construam uma cultura de significados compartilhados e interpretem o mundo de maneira semelhante? A linguagem é capaz de fazer isso porque ela opera como um sistema representacional. Na linguagem, fazemos usos de signos e símbolos - sejam eles sonoros, escritos, imagens eletrônicas, notas musicais e até objetos - para significar ou representar para outros indivíduos nossos conceitos, ideias e sentimentos. A linguagem é um dos 'meios' através do qual pensamentos, ideias e sentimentos são representados numa cultura. A representação pela linguagem é, portanto, essencial aos processos pelos quais os significados são produzidos - e é esta a ideia primordial e subjacente que sustenta este livro. (HALL, 2016, p. 18, grifo do autor). 
Ao compreendemos a cultura como significados compartilhados, torna-se primordial a discussão sobre o meio pelo qual esses significados são compartilhados. Ao passo que admitimos expressar o mundo por meio da linguagem, admitimos também que à medida que esse mundo muda e se reinventa também precisamos adequá-lo dentro desse sistema representacional citado pelo autor.

Sobre a definição de cultura, o autor discute que é "um dos conceitos mais complexos das ciências humanas e sociais" (HALL, 2016, p. 19), uma vez que ele foi sendo re-significado no decorrer do tempo, de forma a ter diferentes significados. Tradicionalmente, cultura esteve atrelada a "alta cultura" ou a "cultura erudita", portanto, ela era produzida por alguns e nem todos tinham acesso, podendo ser encontrada apenas nos clássicos da literatura, na pintura ou em outras manifestações artísticas e intelectuais privilegiadas.

Por outro lado, quando concebíamos uma "alta cultura", considerada de elite, também considerávamos a ideia de cultura tida como "inferior", produzida e compartilhada por "pessoas comuns", denominada de "cultura popular". Nessa perspectiva, atribuíamos uma "alta cultura" que era importada, tomada de empréstimo e, mais a frente, uma cultura local, denominada de "popular".

Diferente dessas duas concepções, privilegiou-se, com o passar do tempo, uma dimensão mais sociológica de cultura, sem, contudo, atribuir um juízo de valor, ao dividi-la em "boa" ou "inferior". Além disso, cultura deixou de significar apenas aquilo que caracteriza um grupo pelo seu "modo de vida", ou seja, seus hábitos e costumes - definição antropológi$\mathrm{ca}$-, e passou a corresponder aos valores e aos saberes compartilhadas por um determinado grupo, sendo essa a definição sociológica. Sendo assim,

\begin{abstract}
nos últimos anos, porém, em um contexto mais próximo das ciências sociais, a palavra 'cultura' passou a ser utilizada para se referir a tudo o que seja característico sobre o 'modo de vida' de um povo, de uma comunidade, de uma nação ou de um grupo social - o que veio a ser conhecido como a definição 'antropológica'. Por outro lado, a palavra também passou a ser utilizada para descrever os 'valores compartilhados' de um grupo ou de uma sociedade - o que de certo modo se assemelha à definição antropológica, mas com uma ênfase sociológica maior. (HALL, 2016, p. 19).
\end{abstract}

Segundo Hall (2016), foi a partir da "virada cultural" que o conceito de cultura deixou de significar apenas um conjunto de coisas produzido pelo homem, tal como a música e as artes em geral, para ser compreendida como um conjunto de práticas sociais; saberes e modos de ver o mundo, compartilhados e mediados pela linguagem. Nesse sentido, para que haja cultura é necessário que haja diálogo entre os sujeitos, de modo que um compreenda o outro e interprete o mundo de forma semelhante:

Basicamente, a cultura diz respeito à produção e ao intercâmbio de sentidos - o
'compartilhamento de significados' - entre os membros de um grupo ou sociedade.
Afirmar que dois indivíduos pertencem à mesma cultura equivale a dizer que eles
interpretam o mundo de maneira semelhante e podem expressar seus pensamentos e
sentimentos de forma que um compreenda o outro. Assim, a cultura depende de que
seus participantes interpretem o que acontece ao seu redor e 'deem sentido' às coisas
de forma semelhante. (HALL, 2016, p. 20).

Para Hall (2006), o conceito de identidade, assim como o conceito de cultura, também foi sendo re-significado no decorrer do tempo. De início, o autor afirma que a definição de 
identidade é algo complexo, tendo em vista que há tendências ambíguas quanto a sua abordagem: de um lado, os teóricos que a concebem como algo fixo; de outro, aqueles que admitem a sua fluidez e mudanças de significado na modernidade tardia que vivenciamos.

Nesse limiar, o autor afirma a impossibilidade de se estabelecer um conceito único e absolutamente verdadeiro, devido as constantes re-interpretações dele no decorrer da história. Desse modo, o teórico discute sobre a própria instabilidade das formulações que ele aborda e afirma o caráter móvel e fluído do conceito de identidade discutido por ele em sua obra:

Consequentemente, as formulações deste livro são provisórias e abertas à contestação. A opinião dentro da comunidade sociológica está ainda profundamente dividida quanto a esses assuntos. As tendências são demasiadamente recentes e ambíguas. O próprio conceito com o qual estamos lidando, 'identidade', é demasiadamente complexo, muito pouco desenvolvido e muito pouco compreendido na ciência social contemporânea para ser definitivamente posto à prova. Como ocorre com muitos outros fenômenos sociais, é impossível oferecer informações conclusivas ou fazer julgamentos seguros sobre as alegações e proposições teóricas que estão sendo apresentadas. Deve-se ter isso em mente ao se ler o restante desse livro. (HALL, 2006, p. 8).

Diante dessa problemática, Hall (2006) aponta três concepções distintas de identidade. A primeira corresponde à identidade do sujeito do Iluminismo, aquele marcado pela constância, um ser que nasce com uma essência interior e que ao longo de sua existência, permanece com os seus processos de identificação inalterados. Em seguida, o autor expõe a noção de sujeito sociológico, no qual a identidade é construída na relação do ser com a sociedade. É importante ressaltar que embora ainda permaneça no sujeito sociológico a noção de essência, admite-se que ela é modificada na relação do eu com o outro. Por último, o autor debate sobre o sujeito pós-moderno que possui uma identidade fragmentada, sendo ela composta de várias identidades. Nessa discussão,

argumenta-se, entretanto, que são exatamente essas coisas que agora estão 'mudan-
do'. O sujeito, previamente vivido como tendo uma identidade unificada e estável,
está se tornando fragmentado; composto não de uma única, mas de várias iden-
tidades, algumas vezes contraditórias ou não-resolvidas. Correspondentemente, as
identidades que compunham as identidades sociais 'lá fora' e que asseguravam nossa
conformidade subjetiva com as 'necessidades' objetivas da cultura, estão entrando
em colapso, como resultado de mudanças estruturais e institucionais. O próprio pro-
cesso de identificação, através do qual nós projetamos em nossas identidades cultu-
rais, tornou-se mais provisório, variável e problemático. (HALL, 2006, p. 12).

A instabilidade dos conceitos de cultura e identidade nos leva a duvidar de qualquer tentativa de homogeneização deles. Hall (2006) destaca que ainda há o interesse em estabelecer uma cultura e uma identidade nacional, anulando, assim, todas e quaisquer diferenças existentes entre elas. Contrários a essa linha de pensamento, observamos a complexidade desses conceitos e como eles revelam a nossa própria pretensão em unificar e materializar aquilo que é - a nosso ver - de caráter mais simbólico do que material. É nessa fluidez que os conceitos são re-imaginados, a fim de "dar conta" das relações sociais moventes, que forjam novos saberes, culturas e também identidades. 


\title{
CONCEITOS HÍBRIDOS EM RESPOSTA À COMPLEXIDADE DAS RELAÇÕES SOCIAIS
}

Haesbaert (2008) propõe que a Geografia, bem como os seus conceitos tradicionais estão relacionados com a cultura, de modo que "Toda Geografia é Geografia cultural", isso porque não há "espaço produzido que não o seja através da cultura dos grupos que o constituem" (2008, p. 396). Esse espaço físico e material, portanto visível e palpável é um objeto interessante de estudo, mas que quando está relacionado à cultura dos sujeitos que ocupam esse espaço, bem como às suas relações com a terra, o rio, a natureza, o sagrado, a memória, a transmissão de saberes, tornam esse "espaço" um lugar que além de físico, é, por excelência, simbólico.

É assim que o autor tece a sua fabulosa argumentação para nos transportar para um espaço que só existe enquanto práticas culturais. Essa Geografia Cultural dá-se nessa relação imbricada entre o material e o simbólico, entre o espaço físico e as relações culturais, históricas, econômicas e políticas que nesses espaços se engendram. Desse modo,

\begin{abstract}
defendemos então o comprometimento com uma visão de Geografia Cultural a partir do que denominamos de abordagem integradora, ou seja, que ao invés de tratar o cultural como uma simples esfera bem delimitada do espaço social, compreende-o em suas múltiplas e indissociáveis articulações com outras dimensões, como a econômica e a política. Esta visão integrada ou integradora do cultural é claramente manifestada em debates contemporâneos que, mais do que se colocarem como debates internos a uma determinada 'Geografia Cultural', trabalham, antes de mais nada, as intersecções, as imbricações ou os limiares entre cultura, política, economia e a própria natureza. Talvez pudéssemos afirmar que as grandes 'perspectivas' - e mesmo alguma das grandes 'questões' - da chamada Geografia Cultural, hoje, estão justamente nas margens, ou, num termo mais adequado, nos cruzamentos, pois nos referimos às combinações, às intersecções, aos pontos de conexão, muito mais do que a pontos marginais ou periféricos. (HAESBAERT, 2008, p. 396).
\end{abstract}

Nessa linha de pensamento, o autor propõe uma abordagem cultural integradora, de modo que os conceitos tradicionalmente criados e dicotomizados se inter-relacionam, sem, contudo, se diluírem. Compreendemos que o aspecto cultural tem as suas especificidades, mas, nessa perspectiva de estudo, privilegia-se as relações que se estabelecem entre cultura e outras dimensões da sociedade, sem, contudo:

diluir a especificidade e a relevância do cultural em si, devemos entendê-lo dentro de concepções não dicotômicas ou dissociativas, mais híbridas, preocupando-nos sempre mais em discutir os vínculos (economia-cultura, cultura-política...), 'numa abordagem cultural integradora', do que em identificar limites e fronteiras. Num mundo em que, diz-se, vivemos mais (n)o 'cruzar' das fronteiras, trabalhar em áreas bem delimitadas torna-se cada vez mais difícil, e, mesmo, contraproducente. (HAESBAERT, 2008, p. 397).

É interessante pensarmos sobre essa relação do mundo com os conceitos historicamente enraizados, pois tais definições nada mais são do que uma representação do mundo que, no processo crescente de globalização, requer que essas representações sejam repensadas, readequadas e, portanto, atualizadas. Assim, o autor parece preocupar-se em esclarecer que o fato de pensarmos a cultura em sua relação com o todo, considerando esse "cruzar" que torna 
cada vez mais difícil a delimitação das fronteiras, não faz o conceito de cultura perder o seu caráter específico e a sua relevante dimensão social.

Essa superação dos conceitos outrora dualistas - de um lado, o espaço geográfico; do outro, a cultura, a história, a economia e a política - reforçam o caráter dinâmico das culturas no mundo. Dessa forma, o espaço físico e cultural se constitui em realidades móveis, que, por isso, devem ser vistos numa perspectiva integradora:

\begin{abstract}
Esse parece ser o único caminho plausível para, ao mesmo tempo, dar conta da complexidade - e da hibridização - dos fenômenos contemporâneos e não perder a especificidade geográfica de nossas interpretações. Assim, o que propomos aqui como abordagem integradora envolve tanto uma interpretação, a nível epistemológico, que de algum modo integre múltiplas dimensões (cultural, econômica e política, por exemplo) quanto o reconhecimento do caráter híbrido ou múltiplo de muitos dos próprios fenômenos geográficos que efetivamente estamos abordando. (HAESBAERT, 2008, p. 398).
\end{abstract}

Seguindo essa linha de pensamento, o autor aborda sobre a necessidade de se elaborar conceitos "híbridos", pois na própria reinvenção desses conceitos, admitem-se as intersecções entre cultura, economia e política. A partir da análise do autor, na elaboração de novos conceitos, é preciso privilegiar os contatos, as relações intrínsecas e, portanto, híbridas, entre cultura-sociedade, cultura-identidade, cultura-identidade-território, colocando-os em relação aos aspectos históricos e políticos que os envolve, admitindo portanto, a sua complexa multiplicidade e hibridização:

Por isso, hoje, mais do que nunca, os conceitos, muito mais do que marcar diferenças, devem revelar multiplicidades, conexões, superposições, o que implica reconhecer sempre os elos com outros conceitos, na complexidade das questões que pretendemos desvendar. (HAESBAERT, 2008, p. 399).

A partir dessa citação, convém refletir sobre como a realidade recria ou reinventa os conceitos, pois, devido às complexas relações sociais contemporâneas, em que as fronteiras adquirem novos significados e as diferenças se cruzam e se inter-relacionam, parece óbvio que os conceitos devam "revelar" ou representar essa nova realidade apresentada. Desse modo, os conceitos são entendidos pelo autor como "instrumentos" que, além de contribuir na compreensão do real, são imprescindíveis para intervir nesse real.

Nessa direção, os conceitos são criados para compreender e intervir numa dada realidade; como as realidades mudam, eles também necessitam ser relidos e reformulados. Esse movimento de reatualização conceitual é importante para compreendermos a fluidez dos "instrumentos" no qual trabalhamos, e assim, poder enxergar novas possibilidades de leitura, interpretação e intervenção das nossas realidades. Dessa maneira,

é interessante perceber, entretanto, que, mais do que 'refletirem' uma realidade, os conceitos são 'instrumentos', e instrumentos não apenas no sentido analítico, como auxiliares de nossas interpretações, mas também no sentido de instrumentos de intervenção, capazes de, por sua própria formulação, 'intervirem' no real. (HAESBAERT, 2008, p. 399).

Desse modo, a importância dos conceitos não está na definição em si, mas no uso que fazemos deles, ou seja: de que forma esse conceito nos ajuda a compreender a multiplicidade 
e complexidade de uma dada realidade? Além disso, tal como o autor propõe: o que podemos fazer com os conceitos que construímos? Para um leitor mais desatento, parece que está se discutindo apenas abstrações, de forma que os conceitos se tornam simples invenções. Contudo, há de se ponderar que:

\begin{abstract}
Assim como não há ciência 'neutra', não há também 'conceitos' neutros, a-históricos e a-políticos. Se um conceito não é nem a realidade existente, em si, nem uma realidade idealizada ou um projeto politicamente almejado, e se ele faz parte, como componente indissociável, de uma realidade em 'devir', devemos reconhecer que ele está imerso, de alguma forma, na própria transformação da realidade que ele diz re-conhecer. Nesse sentido, a história dos conceitos é também a história de sua aplicabilidade e de sua 'adequação' em termos teóricos e também políticos, seu poder ao mesmo tempo de desvendar e de transformar a 'realidade'. (HAESBAERT, 2008, p. 400).
\end{abstract}

A linguagem é o meio pelo qual se transforma, reinventa e desvenda a realidade, portanto se torna um instrumento de luta, no qual se pode questionar e interrogar os conceitos enquanto abstrações de uma dada realidade. Desse modo, é por meio da linguagem que se cria os conceitos e é também por meio dela que eles são questionados e recriados, haja vista que:

Os conceitos nunca são feitos através de limites ou 'identidades' claras, rígidas, e suas formulações trazem sempre um potencial para releitura e integração com ou mesmo reinvenção de outros conceitos numa 'família' ou 'constelação' de conceitos. (HAESBAERT, 2008, p. 401).

É fato que expressamos o mundo através da linguagem, então, à medida que o mundo muda, devemos também mudá-la, sobretudo os conceitos que usamos nesse sistema representacional proposto por Hall (2016). Novamente é preciso ressaltar que esse "novo" mundo, marcado pelas mobilidades, onde o ir e vir é cada vez mais dinâmico, os conceitos de cultura, identidade e território não podem ser dissociados dos aspectos históricos, políticos e econômicos no qual eles emergem.

Nessa perspectiva, Haesbaert (2008) admite em sua obra que as mobilidades culturais, o contato entre diferentes povos, portanto diferentes vivências, culturas, modos de ser e estar no mundo, ocasionaram novas identidades, nas quais ele denomina de identidades "fluídas e móveis". Novamente o autor propõe repensar os conceitos de cultura, identidade e território, tendo em vista que essas identidades que surgem através desses contatos - por isso "móveis e fluídas" - são, segundo o autor, erroneamente conceituadas como identidades desterritorializadas.

\title{
CULTURAS, IDENTIDADES E TERRITÓRIOS: UMA BREVE DISCUSSÃO
}

Inicialmente, cabe ressaltar que a abordagem desses conceitos será a partir de uma visão integradora proposta por Haesbaert (2008), isto é, interessa-nos muito mais discutir o elo existente entre esses conceitos do que propriamente em defini-los separadamente, impondo a eles uma rigidez que parece não corresponder mais à realidade fragmentada da pós-modernidade.

Chirif (2012) aborda sobre o conceito de identidade pensando mais especificamente na realidade dos indígenas peruanos. No que tange à abordagem conceitual, o autor trata sobre a identidade a partir da sua dimensão cultural, isto é, aprendemos a nossa identidade na re- 
lação e na diferenciação com o outro, o que ele denomina de aprendizagem cultural. Nessa perspectiva, o conceito de identidade deve ser compreendido como um processo, pois,

la identidad no es algo dado sino, más bien, un proceso de asimilación y aprendizaje cultural que nunca concluye, que cambia constantemente y cuyas variaciones se deben tanto a dinámicas internas como a las múltiples influencias del exterior. (CHIRIF, 2012, p. 226).

A afirmação do autor nos ajuda a compreender as identidades como sendo "móveis", sujeitas a constantes mudanças, reinvenções e que nunca se conclui de fato, já que ela é compreendida na relação com o outro e com a sociedade que está em constante mudança. Nessa direção, assim como Hall (2006) e Haesbaert (2007), Chirif (2012) também admite a complexidade do conceito de identidade, bem como o seu caráter fluído:

Sin embargo, algunas de las características de la identidad tienen que ver más con los
procesos de cambio de una sociedad que con el antagonismo con foráneos. No existe
una identidad inmutable, estática. Sociedad y cultura son realidades que conllevan el
cambio. Suponer sociedades estáticas es tener uma visión a-histórica de la realidad.
(CHIRIF, 2012, p. 226).

À medida que o autor estabelece a relação entre identidade, a cultura e a sociedade, fica claro que na pós-modernidade, marcada pela velocidade e fragilização das fronteiras, fica cada vez mais difícil fixar e isolar os conceitos de cultura, identidade e território, pois não podemos mais tratar a própria noção de tempo e espaço de forma rígida, devido as relações sociais cada vez mais fluídas ocasionadas pelos fenômenos da globalização.

Nesse sentido, não abordaremos as identidades enquanto essência, ou seja, identidades rígidas e imutáveis que se fecham para as relações existentes no contato com diferentes grupos, e na própria relação do conceito com as suas dimensões históricas e geográficas. $\mathrm{Na}$ contramão disso, faremos um breve debate em torno das identidades territoriais, a partir de uma abordagem geográfica de identidade, proposta por Haesbaert (2007), e logo em seguida, iremos esclarecer o caráter múltiplo e relacional desse conceito híbrido. Assim,

como sabemos, nossas identidades - em seu caráter mais ou menos múltiplo - são sempre configuradas tanto em relação ao nosso passado, à nossa memória e imaginação, isto é, à sua dimensão histórica, quanto em relação ao nosso presente, ao entorno espacial que vivenciamos, isto é, a sua dimensão geográfica. Nosso intuito, então, neste artigo, é trazer à tona o debate contemporâneo das identidades focalizado a partir de sua dimensão espacial ou, de forma mais estrita, territorial, tanto no que se refere ao seu caráter múltiplo, 'híbrido' e flexível dos territórios - e das identidades quanto às manifestações territoriais - e identitárias - mais fechadas e essencializadas. (HAESBAERT, 2007, p. 33).

Novamente Haesbaert (2007) enfatiza a necessidade de pensarmos os conceitos de forma relacional, isto é, integrados. $\mathrm{O}$ autor inicia o seu artigo expondo a problemática entorno do conceito de identidade, revelando, pois, o seu caráter fluído e de constante mudança, tendo em vista o mundo globalizado e "híbrido" no qual vivenciamos. Além disso, ele discute sobre a "crise de identidade" ocasionada pela fragmentação do Estado-nação, em que estabelecer os limites e as fronteiras territoriais tornou-se cada vez mais difícil. Diante dessa problemática, é preciso esclarecer que: 
As coisas não são tão simples e, ao mesmo tempo em que, por um lado, o nacionalismo e as fronteiras se fragilizam, por outro eles ganham nova relevância. Pretendemos assim desenvolver a ideia de que, apesar de teórica e conceitualmente serem tratados majoritariamente como identidades híbridas, móveis ou mesmo 'flutuantes', as identidades se expressam hoje, na prática, através de uma espécie de continuum que vai desde as identidades mais abertas e explicitamente híbridas (no seu extremo, 'fluídas', embora hibridismo e fluidez não sejam obrigatoriamente sinônimos) até as mais 'rígidas' e (re)essencializadas. Paralelamente a esta múltipla composição identitária teríamos, não exatamente como seu 'reflexo', mas como seu constituinte indissociável e de crescente importância, o território, tanto no sentido mais múltiplo e aberto da 'multiterritorialização' em curso quanto na acepção mais fechada dos processos que propomos denominar de 'reclusão territorial', muitas vezes concomitantes e articulados. (HAESBAERT, 2007, p. 34 grifo do autor).

O autor comenta sobre esse ir e vir cada vez mais frequente quando se trata das identidades e faz a abordagem delas em relação ao conceito de território, sendo ele também compreendido ora numa perspectiva mais fechada e ora numa perspectiva mais múltipla. Em seguida, ele revela a tensão no qual todos nós estamos inseridos em tratarmos as identidades como únicas, estáveis e essencializadas, ou, a concebermos como identidades múltiplas e abertas, pois,

hoje, num mundo de 'hibridismos' como o nosso, os conceitos estão longe de carregar a ambição formal de outrora, e às vezes também aqui precisamos trabalhar muito mais com as intersecções e ambivalências do que com fronteiras ou limites claramente definidos. (HAESBAERT, 2007, p. 37).

Na perspectiva do hibridismo cultural, Haesbaert (2007) tece a sua argumentação discutindo sobre a relação existente entre cultura, identidade e território, que para ele, é um elo indissociável. A fim de desconstruir a lógica dos conceitos que correspondem às unicidades, o autor aborda que os conceitos são criados em contraste com outros já estabelecidos, de tal modo que é difícil concebê-los dicotomicamente, já que os conceitos não são criados pela separação, mas pela relação existente entre eles. Nessa linha de pensamento, é importante compreender o conceito de identidade e diferença:

Com relação a identidade e diferença ocorre um cruzamento ainda mais íntimo, pois não há como 'identificar-se' algo sem que sua 'diferenciação' (em relação ao 'outro') seja construída, a ponto de 'diferenciar-se' e 'identificar-se' tornarem-se completamente indissociáveis - isto demonstra, de saída, o caráter permanentemente relacional da construção identitária, sempre produzida na relação com aquele que é estabelecido como o seu 'outro'. (HAESBAERT, 2007, p. 36).

No que se refere ao conceito de território, Haesbaert (2008) comenta que esse é um dos conceitos mais antigos da Geografia e que está sempre atrelado às relações de poder da sociedade. Sendo assim, em outra obra, o autor discorre mais amplamente sobre as definições de território:

Território, por sua vez, aparece ao longo do tempo e na maior parte das reflexões teóricas como conceito capaz de apreender uma das principais dimensões do espaço geográfico, a sua dimensão política ou vinculada às relações de poder, dentro das diferentes perspectivas com que se manifesta o poder. (HAESBAERT, 2007, p. 36). 
Assim, o autor defende que a elaboração dos conceitos, bem como as suas ressignificações e reelaborações estão perpassadas pelas relações de poder. Desse modo, urge a necessidade de pensá-los sempre em relação ao aspecto histórico, social e político no qual eles emergem, tendo em vista que não existem definições ingênuas, muito menos neutras, mas sempre articuladas com as mais diversas relações de poder existentes na sociedade. Sobre a dinamicidade dos conceitos, é importante destacar que:

Como os conceitos nunca são feitos através de limites ou 'identidades' claras, rígidas, e suas significações trazem sempre um potencial para releitura e integração com ou mesmo reinvenção de outros conceitos, território e territorialidade também se inserem nesta abordagem de alguma forma 'híbrida'. (HAESBAERT, 2007, p. 38).

Partindo desse pressuposto, o conceito de território tem sido elaborado a partir da sua dimensão física ou simbólica. Do ponto de vista da abordagem mais simbólica, o autor critica o entendimento equivocado de que exista uma desterritorialização, isto é, à medida que a noção de tempo e espaço se diluem e os contatos entre os grupos sociais se intensificam, os sujeitos se desterritorializam. Ao contrário disso,

muito mais do que perderem vínculos de identificação com espaços determinados, 'desterritorializando-se', o mais comum é que as pessoas e os grupos sociais desenvolvam, concomitantemente, vínculos identitários com mais de um território ao mesmo tempo, ou com territórios que em si mesmos manifestam características muito mais instáveis, múltiplas e/ou híbridas. (HAESBAERT, 2007, p. 49).

O autor defende que ao invés de haver a desvinculação dos sujeitos com o seu território de origem, eles desenvolvem vínculos com diferentes territórios. No que concerne à identidade territorial, lembrando que esse é um conceito mais híbrido e nos ajuda a compreender que a identidade também é construída na relação com o território físico e simbólico, é importante compreender que:

Assim, no que estamos denominando aqui de identidades territoriais, escolhem-se, (ou, concomitantemente, reconstroem-se) espaços e tempos, geografias e histórias para moldar uma identidade, de modo que os habitantes de um determinado território se reconhecem, de alguma forma, como participantes de um espaço e de uma sociedade comuns. (HAESBAERT, 2007, p. 44).

As identidades territoriais, diferente das puramente sociais, tem o território como um elemento definidor e reconstrutor nesse processo de identificação, de modo que:

Em trabalho anterior, ressaltamos que, se toda identidade territorial é, obviamente, uma identidade social, nem toda identidade social (como a identidade de gênero, por exemplo) é, obrigatoriamente, uma identidade territorial. Esta se caracteriza como a identidade social que toma como seu referencial central, definidor do grupo, o território ou, num sentido mais amplo, uma fração do espaço geográfico. (HAESBAERT, 2007, p. 44).

Nessa linha de pensamento, Haesbaert (2007) defende que toda identidade territorial é uma identidade social, mas nem toda identidade social é territorial, isso porque a construção da identidade territorial requer o território como elemento "fundador" dessa identidade. A exemplo de estudos que abordam as identidades territoriais, Morais (2016) aborda o discurso oficial em torno do conceito de "acreanidade" a partir da sua dimensão histórica, geográfica 
e política, a fim de compreender como se forjou uma identidade acreana e como ela é pretensamente reinventada para atingir interesses políticos. O próprio título da obra, expressa o caráter fluído das identidades, no qual elas são inventadas e reinventadas no decorrer do tempo, reforçando a compreensão das identidades como um continuum, como um vir a ser, em sua dimensão plural, tal como afirma Haesbaert (2007).

Inicialmente, Morais (2016) ressalta que os eventos históricos ocorridos em terras acreanas foram fundamentais para que as identidades dos acreanos fossem inventadas e reinventadas, sempre impulsionadas por questões políticas e econômicas. No que diz respeito a relação da identidade com o território e a esses movimentos históricos, é importante compreender que:

A questão territorial perpassa a construção identitária da 'acreanidade'. O território é o estruturador dos três eventos históricos acionados nessa construção identitária. Isto é: na Revolução Acreana (o mito fundador do Acre e dos acreanos), o território significa um recurso econômico e também desempenha um papel simbólico na construção do acreano. O território dos altos rios (ricos em hevea) foi ocupado, explorado e conquistado por 'brasileiros do Acre'. Com a assinatura do Tratado de Petrópolis, o território é o 'fundador' da identidade territorial, o substrato espacial da unidade política administrativa e do povo, agora acreano. Com o Movimento Autonomista, o território conquistado pelos acreanos e 'abandonado' pelo Governo Federal é o estruturador em torno do qual se constrói o discurso acreanista e, com o Movimento Social de Índios e Seringueiros, a questão da defesa territorial, a partir da qual é construído o discurso da defesa da floresta. Toda essa estruturação é perpassada pela formação econômica do Acre, isto é, pela 'sociedade da borracha' em seus altos e baixos e pela tensão com a questão da frente agropecuária. (MORAIS, 2016, p. 29, grifo da autora).

A autora enfatiza que a construção do discurso identitário acreano perpassou por movimentos históricos específicos que tinham a questão territorial como o elemento estruturador. Nessa perspectiva, Morais (2016) afirma que foi a partir da Revolução Acreana, marcada pela luta das terras e pelo anseio dos "revolucionários" que o Acre se tornasse um estado independente, e que, portanto, nasce e se constitui de fato o acreano:

Assim como a história do Acre começa com o extrativismo da borracha, o discurso
identitário que inventa o Acre e os acreanos advém dessa relação da 'sociedade da
borracha' com o território. A disputa entre 'brasileiros do Acre' e bolivianos foi uma
disputa por território, tanto no sentido econômico, quanto no político. No sentido
econômico, está a questão dos recursos econômicos, das árvores de seringa e a terra
de onde nascia a 'árvore de leite' e, no sentido político, estão às argumentações dos
'revolucionários do Acre', em virtude do fato do território ser ocupado majoritaria-
mente por brasileiros do rio Acre. O território em disputa pelos brasileiros do rio
Acre e o governo boliviano é acionado como estruturador da identidade acreana.
O território dos seringais foi ocupado, explorado e defendido durante quatro anos,
sem que o governo brasileiro tomasse partido dos revolucionários. O território, nesse
sentido, é o 'lugar fundador' da identidade, mas ele só se torna fundador porque o
discurso identitário o investe deste papel. (MORAIS, 2016, p. 32).

$\mathrm{Na}$ construção do discurso identitário acreano, o território é o elemento central, tendo em vista que o momento histórico que marca e funda o acreano é envolto pela disputa do território. Desse modo, quando os "revolucionários" até então advindos de outros lugares, 
tais como Ceará, Maranhão, Pernambuco - portanto com uma identidade não pertencente ao território do Acre - conquistam as terras da borracha, a identidade acreana é inventada. Nessa direção,

o acreano, enquanto povo, foi inventado a partir do evento Revolução Acreana; antes, não existiam acreanos nos altos rios e, sim, cearenses, maranhenses, pernambucanos, rio grandenses - ligados ao extrativismo da borracha -, e árabes, portugueses, sírios, libaneses, turcos - ligados ao comércio de mercadorias; todos viviam nos rios Acre, Purus, Xapuri, Iaco, Caeté e tantos outros. Esse povo só passou a ser denominado de acreano após a criação do Território Federal do Acre, em 1904. (MORAIS, 2016, p. 93).

Em seguida, a autora aborda que no Movimento dos Autonomistas, a questão do território é novamente enfatizada como sendo o mito fundador da identidade dos acreanos. Mais à frente, indígenas e seringueiros se organizaram em movimentos sociais em defesa das suas identidades territoriais, isto é, em defesa dos seus "vínculos territoriais" com o Acre. A partir da abordagem desses momentos históricos, a autora defende que esses "são os três eventos históricos trazidos para o presente pelo 'Governo da Floresta' e que foram re-significados em torno da 'acreanidade'”. (MORAIS, 2016, p. 62). Sendo assim, para forjar o discurso da "acreanidade", foi necessário relembrar e refazer os vínculos por meio da memória e dos fatos históricos que simbolizam a luta pelo território e pela identificação com ele, como elementos reconstrutores de um imaginário capaz de erigir re-significações identitárias marcadas pelo interesse político, bem como a conquista e manutenção do poder de partidos.

A autora aborda o conceito de território a partir das suas múltiplas dimensões, tais como a física e a simbólica, todas elas envolvidas pelas relações de poder mediadas pelo e no espaço. Desse modo, a partir da abordagem de Morais (2016), compreendemos que de fato as identidades territoriais são marcadas por essas relações de poder, no qual Haesbaert (2007) descentraliza esse poder e não o atribui somente ao poder do Estado, mas aquele que perpassa as diversas relações sociais. A partir da obra de Morais (2016), notamos o caráter "móvel" dos conceitos, pois ao passo que o território é um elemento central das identidades territoriais, ele também é re-significado pelos interesses políticos que o perpassa e pelas relações de poder estabelecidas na sociedade.

\section{CONSIDERACTOESS FINAIS}

Discutimos brevemente os conceitos de cultura, identidade e território nos seus processos de mudança, considerando que esses são conceitos que refletem uma dada realidade em si, mas que sobretudo, são importantes meios de intervenção nesse real. Além disso, buscamos evidenciar a hibridização dos conceitos, de modo a pensá-los não mais na elaboração de dicotomias, mas nos pontos em que eles se encontram e se entrelaçam.

Compreendemos que significamos e re-significamos o mundo através da linguagem. Portanto, os conceitos carregam em si um caráter móvel, pois na medida em que o mundo se modifica, nós também modificamos a linguagem para compreender uma nova realidade e nela intervir. Nesse caminho, abordamos as identidades territoriais, isto é, aquelas que tem o território como um elemento primordial na construção do discurso identitário para entendermos melhor como os conceitos se hibridizam e se inter-relacionam. 


\section{CULTURES, IDENTITIES AND TERRITORIES: THE REINVENTION OF CONCEPTS \\ MEDIATED BY LANGUAGE}

ABSTRACT: We propose to make in this work a brief theoretical discussion of the concepts of culture, identity and territory, understanding their "mobile" character, as well as the relationship with the historical, political and economic aspects in which they are inserted. Hall (2006) states that it is through language that we mean the world and give meaning to our social relationships. As we re-signify the world and these relationships, we also change the way we express them through language. Haesbaert (2008) addresses the need to think about such concepts from an integrating perspective, as approaching them in a dichotomous way doesn't seem to correspond to the increasingly dynamic society in which we live. From these discussions, we approach territorial identities from the research of Morais (2016), in order to understand this hybrid concept, as well as its historical, political and economic implications in the context of the identity construction of Acre.

KEYWORDS: Cultures. Identities. Territories.

\section{REFERÊNCIAS}

CHIRIF, A. Identidad, interculturalidad e inclusión en la Amazonía peruana hoy. In: TOCHE, E. Perú hoy: La gran continuidade. Lima: Centro de Estudios y Promoción del Desarollo, 2012, p. 223244.

HAESBAERT, R. Hibridismo, mobilidade e multiterritorialização numa perspectiva geográficocultural integradora. In: SERPA, Ângelo (org.). Espaços culturais: vivências, imaginações e representações. Salvador: EDUFBA, 2008.

HAESBAERT, R. Identidades territoriais: entre a multiterritorialidade e a reclusão territorial. In. Identidades e Territórios: questões e olhares contemporâneos. Rio de Janeiro: Acess, 2007.

HALL, S. A identidade cultural na pós-modernidade. Tradução de Tomaz Tadeu da Silva, Guacira Lopes Louro. 11. ed. Rio de Janeiro: DP\&A, 2006.

HALL, S. Cultura e representação. Tradução de Daniel Miranda e William Oliveira. Rio de Janeiro: Ed. PUC-Rio: Apicuri, 2016.

MORAIS, M. J. "Acreanidade": invenção e reinvenção da identidade acreana. Rio Branco: Edufac, 2016.

Data submissão: 06/06/2020

Data aprovação:01/07/2020 